\title{
Effects of Physical Activity on Cognitive Abilities of Dementia Person
}

\section{Bojan Bjelica a, ${ }^{*}$ (D) Nikola Aksović b (D), Laishram Santosh Singh c, Ljubica Milanović a (D), Milan Zelenović a (iD}

a Faculty of Physical Education and Sport, University of East Sarajevo, Pale-71420, Bosnia and Herzegovina

b Faculty of Sport and Physical Education, University of Niš, Niš 18000, Serbia

c Department of Physical Education and Sports Science, Manipur University, Canchipur Manipur-795003, India

*Corresponding author Email: vipbjelica@gmail.com

DOI: https://doi.org/10.34256/ijpefs2135

Received: 05-06-2021, Revised: 02-07-2021; Accepted: 11-07-2021; Published: 12-07-2021

Abstract: The concept of dementia is associated with cognitive changes, behavioral changes, as well as daily motor actions and life functions. The association of physical activity with dementia is a controversial topic in science and is always an interesting basis for discussion among researchers. Moderate PA can be an effective means of reducing the rate of dementia as well as behavioral problems, however caution should be approached when working with this group of people, especially when setting end goals. Given the division of dementia, each person needs to be approached individually and appropriate selection made. The contribution of PA is irreplaceable compared to any type of therapeutic treatment, it improves basic life functions, reduces the mortality rate and improves the quality of life.

Keywords: Alzheimer's, Exercise, Older people, Brain health, Prevalence, QOL

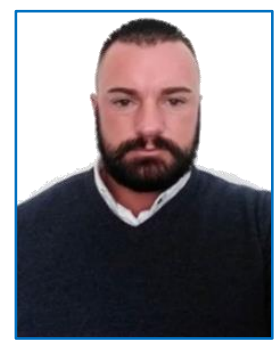

Mr. Bojan Bjelica was born on 14th September 1987 in Sarajevo, the municipality of Centar. He completed his bachelor's and Masters in Physical Education. Since April 2014, he is working as an assistant in the Faculty of Sport and physical education in East Sarajevo on the subject SPORTS RECREATION. Besides, from 2017 he is also working at the Faculty of Economy in Pale as an assistant on the subjects: ECONOMY OF SPORT, ECONOMY OF SPORT RECREATION. Currently, he is doing his doctoral studies in Niš, Republic of Serbia. Since 2016 he is an active member of the ANTHROPOLOGICAL SOCIETY OF SERBIA. Besides his research, he is also serving as an Editorial board member for many international journals.

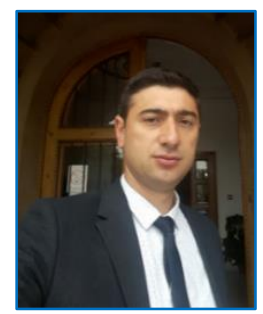

Dr. Nikola Aksović. He completed his doctoral academic studies at the Faculty of Sports and Physical Education, University of Nis, Serbia, with an average grade of 9.79. He defended his doctoral dissertation on November 13, 2019. entitled: "Effects of plyometric training on explosive strength, sprint and speed of change of direction of young basketball players." Acquired title: Doctor of Science - Physical Education and Sports. So far, as an author and co-author, he has published 29 scientific papers and also he is an active reviewer for many international journal.

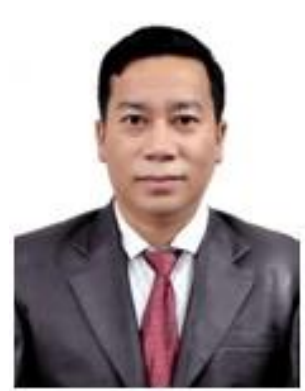

Dr. L. Santosh Singh, working as an Assistant Professor at the Department of Physical Education and Sports Science, Manipur University, Canchipur, Imphal. He completed his undergraduate BPE (1998 2000) from HVPM, Degree College of Physical Education, Amravati, Maharashtra, and postgraduate MPED (20002002)from the same University. He obtained his PhD (2005-2008) from Manipur University, Canchipur, Imphal-Manipur. 


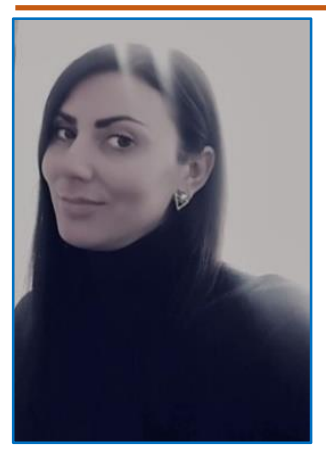

Mr. Ljubica Milanović, M.Sc., was born on September 12, 1985 in Vlasenica. After graduating from high school, in 2004, she enrolled at the Faculty of Physical Education at the University of East Sarajevo, graduating in 2008 as an award-winning student by the faculty's dean. Along with this she also acquired the title of the graduate pedagogue. She enrolled in postgraduate studies immediately after completing her undergraduate studies and received the Master of Science in Physical Culture title in 2010. Currently she is doing her PhD at the Faculty of Sports and Physical Education in Nis. Since 2020, she has been working at the Faculty of Physical Education and Sports of the University of East Sarajevo as a senior assistant.

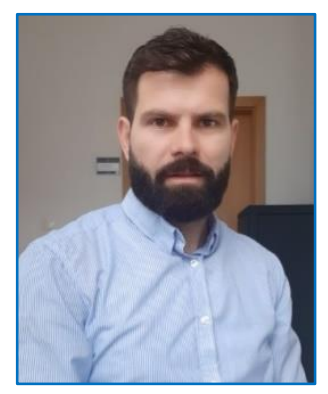

Mr. Milan Zelenović was born in 1987 in Sarajevo. He graduated (Thesis: The main role of playmakers in attack and defense) and obtained his master's degree (Master's thesis: differences in the degree of nutrition of primary school students, athletes and non-athletes) at the Faculty of Physical Education and Sports, University of East Sarajevo-Bosnia and Herzegovina, where he is also employed as an assistant professor for the narrow scientific field of sports and rehabilitation science Kinesiology of collective sports. He is currently working on his doctoral thesis at the Faculty of Sports and Physical Education, University of Nis, Serbia. He played basketball professionally for several clubs in Bosnia and Herzegovina. He worked as a teacher and professor of physical education in several primary and secondary schools and as a coach in basketball clubs. Within the ERASMUS + KA1 program, he taught at the University of Nis at the Faculty of Sports and Physical Education.

\section{Introduction}

Physical activity (PA) provides great opportunities for improving and preserving health, including reducing the risk of various diseases and improving functional abilities [1] associated with poorer mental, physical and social health [2-6]. Physical activity $(\mathrm{PA})$ is a very important segment in health care and development [7]. Research shows that increasing
PA provides comprehensive health benefits and reduces mortality associated with any cause, regardless of body mass index [8]. Physical inactivity was considered a global health problem of one nation. PA has positive relationships with health and life expectancy $[9,10]$. More than half of respondents who start any of the exercise programs to increase physical activity stop within a few months [11]. In this case, it is necessary to pay much more attention when motivating. PA has a positive effect on perception, concentration [12] and self-esteem [13-15], while simultaneously reducing anxiety and stress $[16,17]$. It has a preventive and therapeutic effect on several diseases and conditions and contributes to the quality of life in many ways [18-20]. Epidemiological studies are increasingly proving that PA and exercise can prolong the onset of dementia, and reduce the progression of this condition when it comes to people over the age of 60 . There is growing evidence from epidemiological studies that a history of exercise or physical activity may delay the onset and progression of dementia in older adults [21, 22]. Most of the research conducted to examine the effects of PA on people with dementia includes a sample taken from nursing homes [23, 24], but this population lacks room for PA, which greatly exacerbates the decline in physical fitness [25]. The aforementioned physical readiness is a very important factor in many activities such as walking, climbing stairs and simpler activities such as getting up, performing basic hygiene and the like [26]. Longitudinal studies of surveyed men and women, the results indicate that the mortality rate of people with dementia is significantly lower compared to the sedentary population [27]. Also, some of the studies with a large sample of respondents point out that PA can reduce the degree of dementia by $28 \%$ [28]. The aim of the study was to highlight the positive effects of PA on the cognitive abilities of people with dementia.

\section{Classification and Diagnosis of Dementia}

Alzheimer's (AD) accounts for the highest percentage of this disease, up to $80 \%$ [29]. Aging is the highest risk factor for dementia, the percentage is as much as $90-98 \%$ of people over 65 with some type of dementia or certain cognitive impairment [30,31]. The primary term "dementia" is divided into four output types of dementia: Alzheimer's, Vascular dementia, Levi's, and Frontotemporal dementia [32]. $A D$ is the most common form of dementia. It is formed 
by the deposition of beta-amyloid plaques, with the center in the entorial cortex and hypothalamus, and this causes neuronal damage, followed by total neuronal destruction. By spreading to other parts of the brain, other neural units are destroyed and the disease itself worsens [33]. The types of this disease can be cognitive (loss of memory, loss of objects, etc.) and non-cognitive (depression, aggression, hallucinations, etc.). This type of dementia in the final stages leads to the impossibility of movement, tracking objects, deep delirium, etc. [34, 35]. Vascular dementia is becoming more common, especially due to a sedentary lifestyle, and is caused by a reduced supply of oxygen to the brain. In addition to the most common symptom, stroke, very common disorders are: confusion, depression, poor speech power and the like. Detailed view on Figures 1. - mild cognitive impairment. Similar to AD, Levi's dementia is caused by the formation of alpha-synuclein protein deposits. Patients have a problem with attention, alertness, frequent "staring" at certain objects [36]. Frontotemporal dementia most often occurs at a younger age (starting at the age of 40 ). The most common symptoms of this type of dementia are personality changes and behavioral disorders. This type of dementia affects the frontal and temporal lobes of the brain [37]. Patients with dementia, they have a significant reduction in the ability to remember, but also a significantly reduced insight into this issue. Due to the characteristics of the disease itself and the previous allegation, patients very rarely come for an examination on their own initiative. Patient in the initial stages it quickly forgets some of the information, such as names, dates, days and the like. With the development of the disease itself, especially if it is a type of $A D$, the patient can forget certain events, situations, even information and actions that are of vital importance. By visiting a doctor, it is characteristic that the doctor asks for a certain amount of information from the patient and confirmation from a close family member, so that he can diagnose the severity of the condition and determine further treatment.

\section{FA and Dementia}

The clinical syndrome, which is characterized by cognitive changes, major changes in behavior, problems in motor activities and everyday life functions, is related to the concept of dementia, ie. dementia [38]. Some of the authors estimate that by 2030 the number of people with dementia will be around 65.7 million [39], however, according to the WHO [19], that number is significantly higher and amounts to around 82 million people with dementia. Since there are still no drugs available for this type of disease, physical activity (PA) is the best means of controlling and rehabilitating people with dementia [40, 41] because other alternatives such therapies often lead to side effects and changes in the behavior of patients [42].
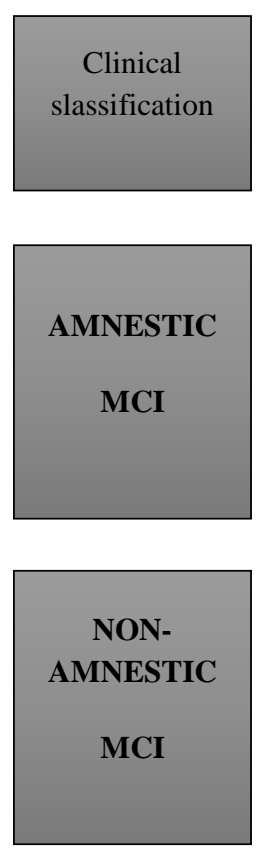
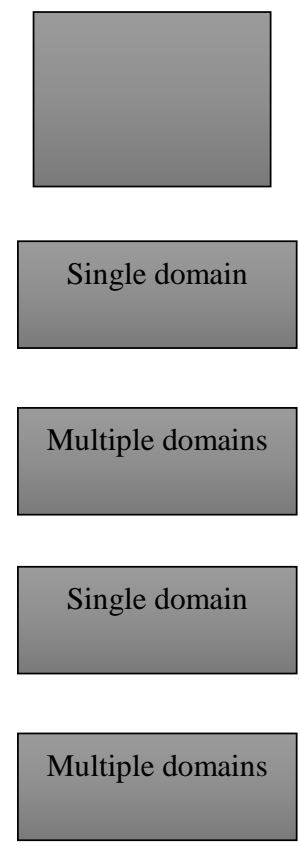

Figures 1. Mild cognitive impairment
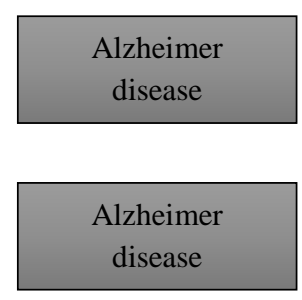
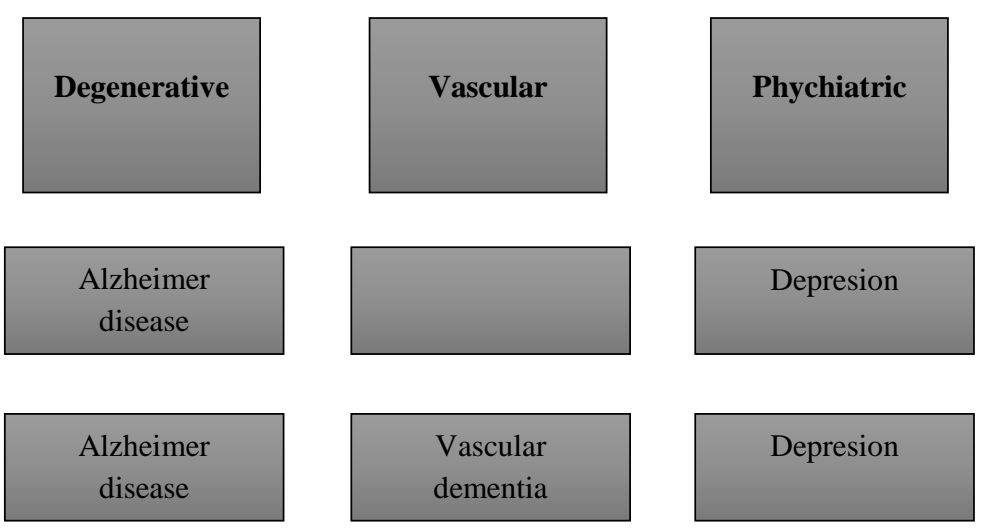

Depresion
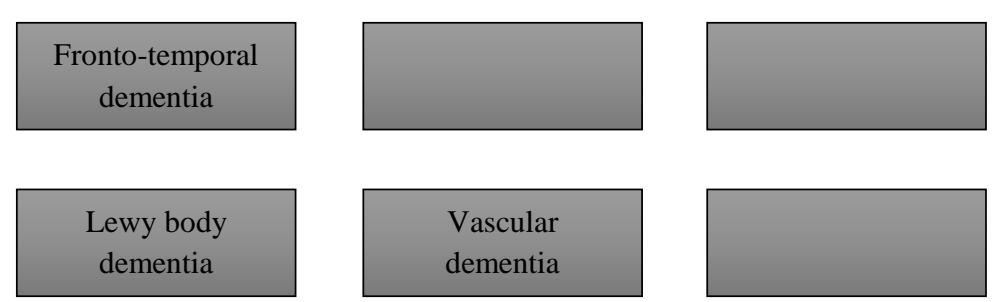
'Exercising PA can have a positive effect on pathogenic by-products that negatively affect a person's behavior [43, 44], also, PA affects the improvement of basic motor functions such as walking, balance, which are otherwise significantly impaired. this disease [45]. Various studies suggest that PA and exercise may to some extent improve cognitive performance in patients with dementia, but it is still unclear which exercise frequency, intensity, time, and type of exercise may better influence cognition improvement in the elderly and adults diagnosed with dementia [46]. Some research points out that exercise plays a significant role in the treatment of people with dementia, however, great caution is emphasized due to the heterogeneity of groups, small number of subjects and other disturbing factors influencing the significance of findings [47, 48]. Taking into account previous findings, PA has a positive effect on reducing risk factors and in addition slows the development of dementia $[49,50]$. People who engage in some form of physical activity almost twice reduce their risk of developing $A D$, from people who belong to an inactive group $[28,51]$. PA should be started in a timely manner in middle age and thus prevent cognitive difficulties and further impairment that would lead to mental and physical changes in the elderly [52]. A large number of authors advise to practice PA type aerobic exercise, walking, running, nordic walking, swimming, cycling, dancing and thus maintain a high degree of cognition [53- 56]. It is concluded that PA has many benefits for people with dementia, however, PA must be individually tailored to the person's mental state and physical abilities [57]. Also a very important factor is achieving good communication due to speech difficulties associated with the disease, understanding of certain requirements, impaired memory, and other difficulties [58].

\section{Research and Exercise Recommendations}

The aim of one study was to examine whether any physical or cognitive recreational activity affects mental activity. The study lasted 21 years and included 469 respondents older than 75 years. According to this study [59], the percentages in which certain mental and physical activities reduce the risk of developing dementia are: Cycling and swimming - $0 \%$ reduced risk; Playing golf - $0 \%$ reduced risk; Reading books reduces risk by $35 \%$ Solving memory games (crossword puzzles, sudoku) at least 4 times a week - by $47 \%$; Frequent dancing - by $76 \%$. In the study [60], an intensive program of strength and balance exercises was conducted, while the subjects of the control group performed light activities of light intensity in a sitting position. The results of the study indicate that the intervention group improved the score on the balance test by an average of 2, 9 points after the intervention, while the control group deteriorated. In the study [61], a customized yoga program was conducted in small groups 3 times a week for 12 weeks, the control group did not have any kind of activity. In the experimental group, observation was increased, depression decreased. This group had better physical and mental status than the control, including, lowered blood pressure, reduced respiratory rate, improved cardiopulmonary fitness, improved body flexibility, improved muscle strength and endurance, improved balance and increased range of motion in the joints. The study [62] included two experimental groups. First, a program of exercises for strength, balance and flexibility, and walking. Second, a supervised walking program. Symptoms of depression were alleviated in both groups.

Exercise recommendations: Exercise should be primarily aerobic in nature; It is desirable that the intensity of exercise be moderate (example: walking, stretching 15-20 minutes per mile); Exercise should last at least 30 minutes and be continuous (preferably every day); Gradually increase the amount of exercise, in order to improve the benefits and health benefits to the maximum; Apply light resistance exercises with additional load at least twice a week to encourage muscle strength and endurance.

\section{Conclusion}

Interventions for PA should have an individual approach in people with dementia. Moderate PA can be an effective means of reducing the rate of dementia as well as improving the cognitive abilities of people already suffering from this type of disease. The contribution of PA is irreplaceable compared to any type of therapeutic treatment, it improves basic life functions, reduces the mortality rate and improves the quality of life. PAs must fit into the daily lives of people with dementia, and with adequate training carefully set the ultimate goal so that people enjoy the activities and reap the best benefits. This study is expected to be an important step in highlighting the importance of PA to public health as well as patients in order to 
reduce the prevalence of this type of disease in the future.

\section{References}

[1] B. Bjelica, Lj. Milanović, N. Aksović, M. Zelenović, D. Božić, Effects physical activity to cardiorespiratory changes, Turkish Journal of Kinesiology, 6(4) (2020) 164-174. [DOI]

[2] A. Holtermann, O.S. Mortensen, K. Sogaard, F. Gyntelberg, P. Suadicani, Risk factors for ischaemic heart disease mortality among men with different occupational physical demands. A 30-year prospective cohort study, BMJ Open, 2(1) (2012) 1-9. [DOI] [PubMed]

[3] H. Arem, S.C. Moore, A. Patel, P. Hartge, A.B. de Gonzalez, K. Visvanathan, P.T. Campbell, M. Freedman, E. Weiderpass, H.O. Adami, M.S. Linet, I.M. Lee, C.E. Matthews, Leisure Time Physical Activity and Mortality: A Detailed Pooled Analysis of the Dose-Response Relationship, JAMA Internal Medicine, 175(6) (2015) 959-967. [DOI] [PubMed]

[4] D. Hupin, F. Roche, V. Gremeaux, J.C. Chatard, M. Oriol, J.M. Gaspoz, J.C. Barthélémy, P. Edouard, Even a low-dose of moderate-to-vigorous physical activity reduces mortality by $22 \%$ in adults aged 60 years: a systematic review and metaanalysis, British Journal of Sports Medicine, 49(19) (2015) 1262-1267. [DOI] [PubMed]

[5] N.C. Barengo, R. Antikainen, K. Borodulin, K. Harald, P. Jousilahti, Leisure-time physical activity reduces total and cardiovascular mortality and cardiovascular disease incidence in older adults, Journal of the American Geriatrics Society, 65(3) (2017) 504-510. [DOI] [PubMed]

[6] G.D. de Oliveira, S.C. Oancea, L.B. Nucci, N. Vogeltanz-Holm, The association between physical activity and depression among individuals residing in Brazil, Social Psychiatry and Psychiatric Epidemiology, 53(4) (2018) 373-383. [DOI] [PubMed]

[7] J.R. Moon, Body composition in athletes and sports nutrition: an examination of the bio impedance analysis technique, European Journal of Clinical Nutrition. 67 (2013) 54-59. [DOI] [PubMed]
[8] V.W. Barry, M. Baruth, M. Beets, L. Durstine, J. Liu, S.N.Blair, Fitness vs. fatness on allcause mortality: a meta-analysis, Progres in Cardiovascular Diseases, 56(4) (2014) 382390. [DOI] [PubMed]

[9] J. Maltby, L. Day, The relationship between exercise motives and psychological well-being, Journal of Psychology, 135(6) (2001) 651-660. [DOI] [PubMed]

[10] M.K. Lustyk, L. Widman, A.E. Paschane, K.C. Olson, Physical activity and quality of life: Assessing the influence of activity frequency, intensity, volume and motives, Behavioral Medicine, 30 (3) (2004) 124-131. [DOI] [PubMed]

[11] K. Allen, M.C. Morey, (2010) Physical activity and adherence. In: Bosworth $\mathrm{H}$ (ed) Improving patient treatment adherence: a clinician's guide, Springer, New York, 9-38. [DOI]

[12] World Health Organization, (2010) Global Recommendations on Physical Activity for Health, World Health Organization, Switzerland.

[13] M.R. Weiss, L. Williams, The why of youth sport involvement: a developmen-tal perspective on motivation processes, In M.R. Weiss (Ed.), Developmental sport and exercise psychology: A lifespan perspective (pp 223268). Morgantown, WV: Fitness Information Technology (2004).

[14] P.R.E. Crocker, C.M. Sabiston, K.C. Kowalski, M.H. McDonough, N. Kowalski, Longitudinal assessment of the relationship between physical self-concept and health-related behavior and emotion in adolescent girls, Journal of Applied Sport Psychology, 18(3) (2006) 185-200. [DOI]

[15] J.A. Moreno, E. Cervelló, R. Moreno, The importance of physical-sport prac-tice and gender in physical self-concept from 9 up to 23 years, International Journal of Clinical Health Psychology, 8(1) (2008) 171-183.

[16] L. Flook, R.L. Repetti, J.B. Ullman, Classroom social experiences as predictors of academic performance, Developmental Psychology, 41(2) (2005) 319-327. [DOI] [PubMed]

[17] P. Dolenc, Anxiety, self-esteem and coping with stress in secondary school students in 
relation to involvement in organized sports, Zdravstveno varstvo, 54(3) (2015) 222-229. [DOI] [PubMed]

[18] Physical Activity Guidelines for Americans, (2008) Be Active, Healthy, and Happy!, U.S. Department of Health and Human Services, Washington.

[19] World Health Organization, (2020) Global resommendations on physical activity to health, Dementia-Rates of dementia.

[20] D.J. Gill, C.C. Hammond, E.J. Reifsteck, C.M. Jehu, R.A. Williams, M.M. Adams, E.H. Lange, K. Becofsky, E. Rodriguez Y.T. Shang, Physical activity and quality of life, Journal of Preventive Medicine \& Public Health, 46(1) (2013) 28-34. [DOI] [PubMed]

[21] R.D. Abbott, L.R. White, G.W. Ross, K.H. Masaki, J.D. Curb, H. Petrovitch, Walking and dementia in physically capable elderly men, Journal of the American Medical Association, 292(12) (2004) 1447-1453. [DOI] [PubMed]

[22] R. Andel, M. Crowe, N.L. Pedersen, L. Fratiglioni, B. Johansson, M. Gatz, Physical exercise at midlife and risk of dementia three decades later: a population-based study of Swedish twins, The Journals of Gerontology: Series A, 63(1) (2008) 62-66. [DOI] [PubMed]

[23] J. Stevens, M.A. Killeen, Randomised controlled trial testing the impact of exercise on cognitive symptoms and disability of residents with dementia, Contemporary Nurse, 21(1) (2006) 32-40. [DOI] [PubMed]

[24] Y. Netz, S. Axelrad, E. Argov, Group physical activity for demented older adults feasibility and effectiveness, Clinical Rehabilitation, 21(11) (2007) 977-986. [DOI] [PubMed]

[25] H. Anderiesen, E.J. Scherder, R.H. Goossens, M.H. Sonneveld, A systematic review-physical activity in dementia: the influence of the nursing home environment, Applied Ergonomics, 45(6) (2014) 1678-1686. [DOI] [PubMed]

[26] K. Hesseberg, H. Bentzen, A.H. Ranhoff, K. Engedal, A. Bergland, Physical fitness in older people with mild cognitive impairment and dementia, Journal of Aging and Physical Activity, 24(1) (2016) 92-100. [DOI] [PubMed]
[27] R. Liu, X. Sui, J.N. Laditka, T.S. Church, N. Colabianchi, J. Hussey, S.N. Blair, Cardiorespiratory fitness as a predictor of dementia mortality in men and women, Medicine and Science in Sports and Exercise, 44(2) (2012) 253-259. [DOI] [PubMed]

[28] M. Hamer, Y. Chida, Physical activity and risk of neurodegenerative disease: a systematic review of prospective evidence, Psychological Medicine, 39(1) (2009) 3-11. [DOI] [PubMed]

[29] W.A. Rocca, R.C. Petersen, D.S. Knopman, L.E. Hebert, D.A. Evans, K.S. Hall, S. Gao, F.W. Unverzagt, K.M. Langa, E.B. Larson, L.R. White, Trends in the incidence and prevalence of Alzheimer's disease, dementia, and cognitive impairment in the United States, Alzheimer's \& dementia, Alzheimer's \& Dementia, 7(1) (2011) 80-93. [DOI] [PubMed]

[30] H. Niu, I. Alvarez-Alvarez, F. Guillen-Grima, L. Aguinaga-Ontoso, Prevalence and incidence of Alzheimer's disease in Europe: a meta analysis, Neurologia, 32, (2017) 523-532. [DOI] [PubMed]

[31] R. Stephen, K. Hongisto, A. Solomon, E. Lönnroos, Physical activity and Alzheimer's disease: a systematic review, The Journals of Gerontology: Series A, 72, (2017) 733-739. [DOI] [PubMed]

[32] W. Muangpaisan, Clinical differences among four common dementia syndromes, Geriatrics \& Aging, 10(9) (2007) 425-429.

[33] C. Reitz, Genetic diagnosis and prognosis of Alzheimer's disease: challenges and opportunities, Expert Review of Molecular Diagnostics, 15(3) (2015) 339-348. [DOI] [PubMed]

[34] B. Sheehan, Assessment scales in dementia, Therapeutic Advances in Neurological Disorders, 5(6) (2012) 349-358. [DOI] [PubMed]

[35] H. Chertkow, H.H. Feldman, C. Jacova, F. Massound, Definitions of dementia and predementia states in Alzheimer's disease and vascular cognitive impairment: consensus from the Canadian conference on diagnosis of dementia, Alzheimer's Research \& Therapy, 5(1) (2013) 1-8. [DOI] [PubMed] 
[36] M. Zupancic, A. Mahajan, K. Handa, Dementia with Lewy bodies: diagnosis and management for primary care providers, Prim Care Companion CNS Disord, 13(5) (2011). [DOI] [PubMed]

[37] Alzheimer Society of Canada. Vascular dementia. Available:

www.alzheimer.ca/en/About-

dementia/Dementias/Vascular-Dementia

(accessed Sep. 19, 2016).

[38] K.R. Scott, A.M. Barrett, Dementia syndromes: evaluation and treatment, Expert Review of Neurotherapeutics, 7(4) (2007) 407-422. [DOI] [PubMed]

[39] M. Prince, R. Bryce, E. Albanese, A. Wimo, W. Ribeiro, C.P. Ferri, The global prevalence of dementia: A systematic review and metaanalysis, Alzheimers Dement, 9 (2013) 63-75. [DOI] [PubMed]

[40] F. Sofi, D. Valecchi, D. Bacci, R. Abbate, G.F. Gensini, A. Casini, C. Macchi, Physical activity and risk of cognitive decline: a meta-analysis of prospective studies, Journal of Internal Medicine, 269(1) (2011) 107-117. [DOI] [PubMed]

[41] H. Öhman, N. Savikko, T.E. Strandberg, K.H. Pitkälä, Effect of physical exercise on cognitive performance in older adults with mild cognitive impairment or dementia: a systematic review, Dementia and Geriatric Cognitive Disorders, 38 (2014) 347-365. [DOI] [PubMed]

[42] D. Galimberti, E. Scarpini, Treatment of Alzheimer's disease: symptomatic and diseasemodifying approaches, Current Aging Science, 3(1) (2010) 46-56. [DOI] [PubMed]

[43] K. Belarbi, S. Burnouf, F.J. Fernandez-Gomez, C. Laurent, S. Lestavel, M. Figeac, A. Sultan, L. Troquier, A. Leboucher, R. Caillierez, M.E. Grosjean, D. Demeyer, H. Obriot, I. Brion, B. Barbot, M.C. Galas, B. Staels, S. Humez, N. Sergeant, S. Schraen-Maschke, A. MuhrTailleux, M. Hamdane, L. Buée, D. Blum, Beneficial effects of exercise in a transgenic mouse model of Alzheimer's disease-like Tau pathology, Neurobiology of Disease, 43(2) (2011) 486-494. [DOI] [PubMed]

[44] C.M. Yuede, S.D. Zimmerman, H. Dong, M.J. Kling, A.W. Bero, D.M. Holtzman, B.F. Timson, J.G. Csernansky, Effects of voluntary and forced exercise on plaque deposition, hippocampal volume, and behavior in the Tg2576 mouse model of Alzheimer's disease, Neurobiology of Disease, 35(3) (2009) 426432. [DOI] [PubMed]

[45] S. Faulk, L. Edwards, K. Sumrall, M. Shelton, Benefits of physical activity on Alzheimer's disease: a literature review, Clinical Kinesiology, 68 (2014) 19-24.

[46] R.X. Jia, J.H. Liang, Y. Xu, Y.Q. Wang, Effects of physical activity and exercise on the cognitive function of patients with Alzheimer disease: a meta-analysis, BMC geriatrics, 19(1) (2019) 181. [DOI] [PubMed]

[47] P. Heyn, B.C. Abreu, K.J. Ottenbacher, The effects of exercise training on elderly persons with cognitive impairment and dementia: a meta-analysis, Archives of Physical Medicine and Rehabilitation, 85 (10) (2004) 1694-1704. [DOI] [PubMed]

[48] L. Buettner, N.E. Richeson, F. Yu, S.C. Burgener, K.C. Buckwalter, E. Beattie, A.L. Bossen, D.M. Fick, S. Fitzsimmons, A. Kolanowski, K. Rose, S.J.K. Pringle, I. Testad, S.E. McKenzie, Evidence supporting exercise interventions for persons in early-stage Alzheimer's disease, American Journal of Recreation Theraphy, 7(1) (2008) 17-24. [DOI]

[49] E. Santana-Sosa, M.I. Barriopedro, L.M. LópezMojares, M. Pérez, A. Lucia, Exercise training is beneficial for Alzheimer's patients, International Journal Sports Medicine, 29(10) (2008) 845-850. [DOI] [PubMed]

[50] N.T. Lautenschlager, K.L. Cox, L. Flicker, J.K. Foster, F. Van Bockxmeer, J. Xiao, K. Greenop, O.P. Almeida, Effect of physical activity on cognitive function in older adults at risk for Alzheimer disease: A randomized trial, The Journal of the American Medical Association, 300(9) (2008) 1027-1037. [DOI] [PubMed]

[51] S. Karceski, Preventing Alzheimer disease with exercise? Neurology, 78, (2012) 110-112. [DOI] [PubMed]

[52] M. Kivipelto, A. Solomon, Alzheimer's diseaseThe ways of prevention, Journal of Nutrition, Health and Aging, 12 (2007) 89-94. [DOI]

[53] S. Rovio, I. Kåreholt, E.L. Helkala, M. Viitanen, B. Winblad, J. Tuomilehto, H. 
Soininen, A. Nissinen, M. Kivipelto, Leisuretime physical activity at midlife and the risk of dementia and Alzheimer's disease, The Lancet Neurology, 4(11) (2005) 705-711. [DOI] [PubMed]

[54] L. Eggermont, D. Swaab, P. Luiten, E. Scherder, Exercise, cognition and Alzheimer's disease. More is not necessarily better, Neuroscience \& Biobehavioral Reviews, 30(4) (2006) 562-575. [DOI] [PubMed]

[55] W.J. Hoyer, P. Verhaeghen, Memory aging. In Handbook of the Psychology of Aging; Birren, J.E., Schaire, K.W., Eds.; Elsevier: Amsterdam, The Netherlands, (2006) 209-232. ISBN: 9780124114692

[56] W. Bouaziz, T. Vogel, E. Schmitt, G. Kaltenbach, B. Geny, P.O. Lang, Health benefits of aerobic training programs in adults aged 70 and over: A systematic review, Archives of Gerontology and Geriatrics, 69 (2017) 110-127. [DOI] [PubMed]

[57] J.L. Helbostad, (2007) Fysioterapi i geriatrien [Physiotherapy in geriatric medicine]. In: Helbostad JL, Granbo R, sterås H, Eds. Aldring og bevegelse. Fysioterapi for eldre. [Ageing and Movement, Physiotherapy for the elderly.] Oslo: Gyldendal Akademiske Forlag, 366-394.

[58] R. Oddy, (2003) Promoting mobility for people with dementia. 2. edn, Age Concerns England, London, UK.

[59] J. Verghese, R.B. Lipton, M.J. Katz, C.B. Hall, C.A. Derby, G. Kuslansky, A.F. Ambrose, M. Sliwinski, H. Buschke, Leisure activities and the risk of dementia in the elderly, New England Journal of Medicine, 348(25) (2003) 25082516. [DOI] [PubMed]

[60] E.W. Telenius, K. Engedal, K. Bergland, Effect of a high-intensity exercise program on physical function and mental health in nursing home residents with dementia: an assessor blinded randomized controlled trial, PLoS One, 10(5) (2015) 1-18. [DOI] [PubMed]

[61] J.T. Fan, K.M. Chen, Using silver yoga exercises to promote physical and mental health of elders with dementia in long-term care facilities, International Psychogeriatrics, 23(8) (2011) 1222-1230. [DOI] [PubMed]

[62] C.L. Williams, R.M. Tappen, Exercise training for depressed older adults with Alzheimer's disease, Aging and Mental Health, 12(1) (2008) 72-80. [DOI] [PubMed]

\section{Funding}

No funding was received for conducting this study

\section{Authors Contribution}

Bojan Bjelica and Nikola Aksović, were included in the study design, literature research and manuscript writing; Laishram Santosh Singh were included in conceptualization, study findings interpretation and manuscript writing; Ljubica Milanović and Milan Zelenović were included in the study methodology design and formal analysis. All authors read and approved the final version of the manuscript.

\section{Conflict of interest}

The Authors have no conflicts of interest to declare that they are relevant to the content of this article.

\section{Does this article screened for similarity? \\ Yes}

\section{About The License}

(C) The Author(s) 2021. The text of this article is open access and licensed under a Creative Commons Attribution 4.0 International License 